\title{
The Influence of Medium Composition on the Growth and Swarming of Proteus
}

\author{
By H. E. JONES* AND R. W. A. PARK \\ Microbiology Department, Reading University \\ (Accepted for publication 12 January 1967)
}

\section{SUMMARY}

The ability of various compounds to support swarming of Proteus was determined by making additions to a minimal medium agar on which swarming did not occur. Swarming occurred when alanine, asparagine aspartic acid, glutamic acid, glutamine, proline or serine were present, either individually or together. It did not occur when certain other amino acids were added individually to minimal medium agar but did occur when these were added together. The ability of a compound to support swarming was correlated with its ability to serve as a carbon + energy source and with the stimulation of growth rate. The swarming phenomenon is discussed in the light of these findings.

\section{INTRODUCTION}

Many members of the bacterial genus Proteus exhibit the phenomenon of swarming when grown on solid medium (Plate 1). When inoculated at the centre of a plate of suitable medium and incubated aerobically at $30-37^{\circ}$ the culture grows as short organisms for a few hours; then organisms at the edge of the colony thus formed elongate and spread over the surface, i.e. they swarm. Movement stops after 1-2 hr. Division of organisms at the edge of the colony then occurs, to give short organisms, and the cycle is repeated. All organisms beyond the edge of the initial colony constitute the swarm. The swarming phenomenon of Proteus has been described by many workers, with slight variations in their descriptions (Hauser, 1885; Moltke, 1927; Russ-Munzer, 1935; Dienes, 1946; Klieneberger-Nobel, 1947; Lominski \& Lendrum, 1947; Kvittingen, $1949 a, b$; Hughes, 1957; Hoeniger, 1964; Jones, 1966). Two theories have been proposed to explain swarming. One is that local over-popuation exhausts the nutrients in the area and that the resultant gradient of nutrients at the periphery encourages outward growth and movement (Moltke, 1927; Russ-Munzer, 1935). The other theory is that swarming is a response to metabolic products which accumulate during growth of the non-swarming organisms (Lominski \& Lendrum, 1947; Hughes, 1957).

There have been few studies of the effect of medium composition on swarming, apart from studies which involved additions of inhibitors to stop swarming, and all previous workers have used complex undefined media. We found that swarming of Proteus mirabilis and $P$. vulgaris did not occur on a solid medium prepared by adding agar to the minimal medium of Fildes (1938), although the organisms did produce

* Present address: Department of Microbiology, Yale University, New Haven, Connecticut, U.S.A. 
flagella on this medium. It was therefore possible by making additions to Fildes medium to determine the ability of various compounds to support swarming. It became clear that many compounds would support swarming; the effect of these compounds on growth was therefore examined.

\section{METHODS}

Organisms. Several Proteus strains were isolated from swarms on blood agar plates obtained through the courtesy of Dr T. D. Martin from the Pathology Department, Royal Berkshire Hospital. Two strains of Proteus mirabilis were chosen for detailed study; these were deposited in the National Collection of Dairy Organisms (NCDO1880, NCDO1881). On nutrient agar both strains gave zoned swarms typical of Belyavin's (1951) 'A' phase (' $Y$ ' variant of Coetzee \& Sacks, 1960). Maintenance was by subculture every 4 months on slopes of soft nutrient agar (see below) dispensed in screw-capped bottles. After incubation at $37^{\circ}$ for $24 \mathrm{hr}$ cultures were stored at room temperature.

Media. All media were prepared using demineralized water from a model $8 \mathrm{E}$ Deminrolit two-cylinder ion exchanger (Permutit, London, W. 4). Nutrient agar consisted of $(\%, \mathrm{w} / \mathrm{v}$, in water) peptone (Evans), $0.5 ;$ Lab-Lemco (Oxoid), $0.5 ; \mathrm{NaCl}$, 0.5 ; New Zealand agar (Davis), 1.2; $\mathrm{pH} \mathrm{7.2}$ before autoclaving $\left(121^{\circ}, 20 \mathrm{~min}\right.$.). For soft nutrient agar $0.8 \%(\mathrm{w} / \mathrm{v})$ agar was used. Nutrient broth was of the same composition apart from the omission of agar. The liquid minimal medium (MM liquid) for Proteus was that of Fildes (1938) but $\mathrm{NaCl}$ was incorporated to ensure sufficient electrolyte for swarming on solid media (Naylor, 1960; Sandys, 1960). Five solutions were prepared; Solution $a$ was $\mathrm{KH}_{2} \mathrm{PO}_{4}, 18.0 \mathrm{~g}$; $\left(\mathrm{NH}_{4}\right)_{2} \mathrm{SO}_{4}, 2.0 \mathrm{~g}$.; $\mathrm{NH}_{4} \mathrm{Cl}, 2 \cdot 0 \mathrm{~g}$; sodium lactate $(70 \%, \mathrm{w} / \mathrm{v}$, aqueous solution), $16.0 \mathrm{~g}$; in $1800 \mathrm{ml}$. water; $\mathrm{pH} 7.6$ before autoclaving $\left(121^{\circ}, 20 \mathrm{~min}\right.$. $)$ : Solution $b$ was $\left.\mathrm{Fe}\left(\mathrm{NH}_{4}\right)_{2}\left(\mathrm{SO}_{4}\right)_{2} \cdot 6 \mathrm{H}_{2} \mathrm{O}, .0 \cdot 08 \% \mathrm{w} / \mathrm{v}\right)$ in $\mathrm{N} / 50 \mathrm{HCl}$, sterilized by filtration through glass: Solution $c$ was $\mathrm{MgSO}_{4} \cdot 7 \mathrm{H}_{2} \mathrm{O}$, $0.4 \%(\mathrm{w} / \mathrm{v})$ in water, sterilized by autoclaving $\left(115^{\circ}, 10 \mathrm{~min}\right.$. $)$ : Solution $d$ was nicotinic acid, $0.012 \%(\mathrm{w} / \mathrm{v})$ in water, sterilized by autoclaving $\left(115^{\circ}, 10 \mathrm{~min}\right.$.): Solution $e$ was $\mathrm{NaCl}, 24.0 \%(\mathrm{w} / \mathrm{v})$ in water, sterilized by autoclaving $\left(121^{\circ}, 20 \mathrm{~min}\right.$.). For use, solutions $a(30 \mathrm{ml}),. b(1.5 \mathrm{ml}),. c(0.6 \mathrm{ml}),. d(1.2 \mathrm{ml}),. e(1.2 \mathrm{ml}$.) were mixed and made to $60 \mathrm{ml}$. with water or with aqueous solutions of test materials. To obtain a minimal medium agar (MM agar) the constituents of solution $a$ (see above) were dissolved in $200 \mathrm{ml}$. demineralized water and added while hot to a hot solution of New Zealand agar (Davis; $43 \cdot 2 \mathrm{~g}$. in $1600 \mathrm{ml}$. water), after which the whole was sterilized by autoclaving $\left(115^{\circ}, 10 \mathrm{~min}\right.$.). For use, $30 \mathrm{ml}$. of this molten agar was cooled to $60^{\circ}$, the same amounts of solutions $b, c, d$ and $e$ as given above were added, and the volume made to $60 \mathrm{ml}$. with water or with aqueous solutions of test materials.

Plates were prepared by pouring about $15 \mathrm{ml}$. molten medium at $55^{\circ}$ into glass Petri dishes (diam. $9 \mathrm{~cm}$.) and drying open for $2 \mathrm{hr}$ at $37^{\circ}$. They were used within $24 \mathrm{hr}$.

Inoculum. Organisms from a nutrient agar slope culture incubated at $37^{\circ}$ for $24 \mathrm{hr}$ were washed once in $\frac{1}{4}$ strength Ringer solution $(50 \mathrm{ml}$.) and then suspended in $3 \mathrm{ml}$. $\frac{1}{4}$ strength Ringer solution to give a dense suspension. Each inoculum was tested to see that it consisted of organisms in the $A(Y)$ phase (see above) by inoculation on two nutrient agar plates and examination after incubation to confirm that a zoned swarm was produced. 
Determination of ability of various compounds to serve as carbon+energy sources and/or nitrogen sources in agar media. For each medium two plates per strain were inoculated by putting one drop $(0.02 \mathrm{ml}$.) of bacterial suspension on the agar surface. After specified periods of incubation the amount of growth at the site of the drop inoculum was compared visually with that on a control medium appropriate to the experiment. The results obtained in this way agreed with results obtained in other experiments where the ability of a medium to support growth was ascertained by measuring the size of the well-isolated colonies, excluding any swarms, on streak plates.

Estimation of growth rate in liquid media. Samples of each medium (10 ml.) were placed in a conical flask $(100 \mathrm{ml}$.) which had a side arm made from a test tube. Inoculum $(0.5 \mathrm{ml}$.) was added and the flasks shaken at $110-120 \mathrm{cyc} . / \mathrm{min}$. in a water bath at $37^{\circ}$. At intervals of $30 \mathrm{~min}$. flasks were removed for turbidity measurements and then quickly replaced. Measurements were made by tipping each flask to get the culture in the side arm which was then put in a nephelometer (Evans Electroselenium, Halstead, Essex). The instrument was adjusted at the start of each experiment to a sensitivity that gave a straight-line relationship over a wide range between turbidity and $\log _{2}$ dilution of a suspension of organisms. Generation times were obtained from readings within this range.

\section{RESULTS}

Survey of substances to determine their ability to support swarming

By using a modification of the auxanographic technique (Beyerinck, 1889; Pontecorvo, 1949), vitamin-free acid hydrolysed casein (Casamino acids, Difco), yeast extract (Difco), yeast nucleic acid (Koch-Lights) or a mixture of 10 water-soluble vitamins were tested for ability to support swarming. A small amount of one of these substances was put on a Proteus inoculum streaked across the centre of a plate of MM agar (Fig. 1) which was then incubated at $37^{\circ}$. Plates treated in this way were examined after $15 \mathrm{hr}$ and $40 \mathrm{hr}$ to see whether any swarming had occurred. Swarming occurred with Casamino acids and with yeast extract but not with the other substances. Examination of the swarms showed that they were similar to those produced on

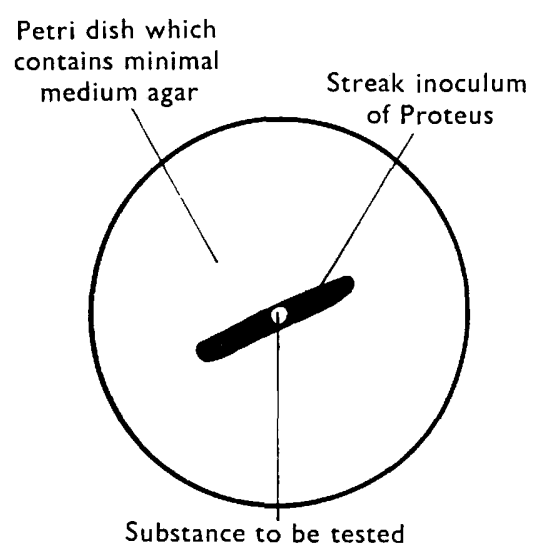

Fig. 1. Diagram to show the technique used to determine the ability of substances to support swarming. 
nutrient agar; zones were present and the swarming edges consisted of long forms. Because the Casamino acids preparation was vitamin-free and because swarming did not occur with the mixture of 10 vitamins it was thought that swarming in the presence of Casamino acids or of yeast extract was due to the amino acid content of these preparations. A subsequent experiment showed that similar swarms occurred in the presence of a mixture of 22 amino acids (listed below).

A more detailed study was then made to determine whether the stimulation of swarming was due to any particular amino acid or group of amino acids. Aqueous solutions of single amino acids, adjusted to $\mathrm{pH} 7 \cdot 2-7 \cdot 8$ with $\mathrm{NaOH}$, were then tested at $\mathrm{M} / 16$ and $\mathrm{M} / 128$ of the $\mathrm{L}$ isomer by addition to $\mathrm{MM}$ agar before plates were prepared. When only DL-mixtures were available these were added to give the required concentration of $L$-isomer, since, although no other D-amino acids were tested, it had been shown that D-glutamic acid did not affect the ability of L-glutamic acid to support swarming. For each strain duplicate plates of each medium were inoculated by putting 1 drop $(0.02 \mathrm{ml}$.) of inoculum on a disc of filter paper (diam. $5 \mathrm{~mm}$.) which was at the centre of the plate. After $15 \mathrm{hr}$ and $40 \mathrm{hr}$ at $37^{\circ}$ plates were examined and any swarms produced were measured along two radii from the edge of the filter paper to the edge of the swarm. No record was made of the number of zones per swarm. Swarms were produced on plates which contained L-glutamic acid, L-aspartic acid, DL-serine, L-proline, DL- $\alpha$-alanine, L-asparagine or L-glutamine, but these were narrower than swarms on plates which contained all these 7 amino compounds together or Casamino acids. No swarming occurred on plates which contained any one of the following: glycine, DL-valine, DL-leucine, DL-isoleucine, DL- $\beta$-phenylalanine, L-tyrosine, DL-methionine, L-cysteine $\mathrm{HCl}$, L-cystine, L-threonine, L-lysine $\mathrm{HCl}$, L-histidine $\mathrm{HCl}$, L-arginine $\mathrm{HCl}$, L-hydroxyproline, DL- $\alpha$-aminobutyric acid. However, swarms were produced when these latter amino acids, with the omission of $\alpha$-aminobutyric acid (which inhibited growth) were incorporated together in MM agar at $\mathrm{M} / 256$ of each amino acid.

\section{Ability of amino acids to serve as carbon +energy sources and/or nitrogen sources in agar media}

The work described above showed that stimulation of swarming by the mixture of 22 amino acids was not due to any single amino acid or to a specific group of amino acids. It was thought that the amino acids must act in some non-specific way, so the possibility that there was a relationship between swarming and increased growth resulting from metabolism of added amino acids was considered. The various amino acids studied were examined for their ability to serve as carbon + energy sources and/or nitrogen sources when added to $\mathrm{MM}$ agar lacking sodium lactate and MM agar lacking $\mathrm{NH}_{4} \mathrm{Cl}$ and $\left(\mathrm{NH}_{4}\right)_{2} \mathrm{SO}_{4}$, respectively. The results (Table 1) showed that only threonine and the 7 amino acids which supported swarming when added to complete MM agar acted as carbon + energy sources. Fifteen amino acids, including all those which served as carbon + energy sources, were each an effective source of nitrogen. Six amino acids supported slight growth, but no growth occurred with hydroxyproline. Swarming did not always occur on media which contained compounds that supported the largest amounts of growth but swarming sometimes occurred on media which did not support so much growth as did MM agar, on which swarming did not occur. 


\section{Growth rates and the ability of media to support swarming}

The results of the previous growth experiments suggested that stimulation of swarming by amino acids was not associated with the total amount of bacteria produced. There was no correlation between the amount of growth at the site of

Table 1. Ability of M/128 L-isomer amino acids to serve as carbon and energy and/or nitrogen sources for Proteus mirabilis strains NCDO, $18801881^{*}$

\begin{tabular}{|c|c|c|c|c|}
\hline \multirow{3}{*}{$\begin{array}{l}\text { Compound } \\
\text { added to appropriate } \\
\text { basal medium }\end{array}$} & \multicolumn{4}{|c|}{$\begin{array}{c}\text { Amount of growth supported after } 65 \mathrm{hr} \text { at } 37^{\circ} \\
\text { when compound was serving as: } \dagger\end{array}$} \\
\hline & \multicolumn{2}{|c|}{ Carbon and energy source } & \multicolumn{2}{|c|}{ Nitrogen source } \\
\hline & Strain 1880 & Strain 1881 & Strain 1880 & Strain 1881 \\
\hline DL- $\alpha$-alanine & +++ & $+t+$ & +++ & $++t$ \\
\hline DL-serine & ++ & $+++\mathrm{S}$ & $++++S$ & $+++S$ \\
\hline L-threonine & + & ++ & ++++ & ++++ \\
\hline L-aspartic acid & + & + & $++++S$ & $+++S$ \\
\hline L-glutamic acid & +++ & $+++\mathbf{S}$ & $+++S$ & $++++S$ \\
\hline L-proline & $+t+t$ & $++++S$ & ++++ & +++ \\
\hline L-asparagine & + & + & $++++S$ & $++++S$ \\
\hline L-glutamine & +++ & $+t+$ & $++++S$ & $++++S$ \\
\hline Glycine & - & - & +++ & +++ \\
\hline L-tyrosine & - & - & $+t$ & $+t$ \\
\hline DL-tryptophane & - & - & ++ & ++ \\
\hline L-cysteine $\mathrm{HCl}$ & - & - & ++ & $+t$ \\
\hline L-cystine & - & - & ++ & ++ \\
\hline DL-methionine & - & - & +++ & +++ \\
\hline L-arginine $\mathrm{HCl}$ & - & - & $++t$ & ++ \\
\hline DL-valine & - & - & + & + \\
\hline DL-leucine & - & - & + & + \\
\hline DL-isoleucine & - & - & + & + \\
\hline DL- $\beta$-phenylalanine & - & - & + & + \\
\hline L-histidine $\mathrm{HCl}$ & - & - & + & + \\
\hline L-lysine $\mathrm{HCl}$ & - & - & + & + \\
\hline $\begin{array}{l}\text { L-hydroxyproline } \\
\text { Controls }\end{array}$ & - & - & - & - \\
\hline $\begin{array}{l}\text { sodium lactate } \\
\mathrm{NH}_{4} \mathrm{Cl}+\left(\mathrm{NH}_{4}\right)_{2} \mathrm{SC}\end{array}$ & ++++ & ++++ & $+t+$ & $+\dot{+}+$ \\
\hline
\end{tabular}

* When tested as carbon and energy sources amino acids were added to MM agar from which sodium lactate was omitted. When tested as nitrogen sources they were added to MM agar from which $\mathrm{NH}_{4} \mathrm{Cl}$ and $\left(\mathrm{NH}_{4}\right)_{2} \mathrm{SO}_{4}$ were omitted.

$\dagger$ Amount of growth, not including growth of any swarms, supported by amino compounds varied from ++++ (maximum growth) to - (same amount of growth as that on MM agar without sodium lactate or without $\mathrm{NH}_{4} \mathrm{Cl}$ and $\left(\mathrm{NH}_{4}\right)_{2} \mathrm{SO}_{4}$ as appropriate).

Amount of growth supported when serving as carbon and energy sources cannot be compared with that supported when serving as nitrogen sources as in each case the amino compound supporting most growth was scored ++++ irrespective of the absolute amount of growth.

S, Swarming occurred.

inoculation and the production of swarms. Furthermore, when swarming did occur it did so before maximum growth had been reached at the inoculum site, i.e. at a time when the amount of growth was less than the maximum produced on media which did not support swarming.

The possibility that swarming was related to the rate of growth was investigated by using strain NCDO 1881. Because of the difficulties involved in measuring growth 
Table 2. Generation times of Proteus mirabilis strain NCDO 1881 in various liquid media and occurrence of swarming on equivalent solid media

\begin{tabular}{|c|c|c|}
\hline Medium & $\begin{array}{l}\text { Generation time } \\
\text { (min.) }\end{array}$ & $\begin{array}{l}\text { Occurrence of } \\
\text { swarming on } \\
\text { equivalent solid } \\
\text { medium after } \\
48 \mathrm{hr} \text { at } 37^{\circ}\end{array}$ \\
\hline \multicolumn{3}{|l|}{ Experiment 1} \\
\hline MM liquid & 108 & - \\
\hline \multicolumn{3}{|l|}{ MM liquid plus the following at $\mathrm{M}-16 \mathrm{~L}$-isomer } \\
\hline L-glutamic acid & 66 & + \\
\hline L-proline & 66 & + \\
\hline L-glutamine & 72 & + \\
\hline \multicolumn{3}{|l|}{ Experiment 2} \\
\hline MM liquid & 120 & - \\
\hline \multicolumn{3}{|l|}{ MM liquid plus the following at M- $128 \mathrm{~L}$-isomer } \\
\hline $\begin{array}{l}\text { Mixture of DL- } \alpha \text {-alanine, L-asparagine, L-proline, } \\
\text { L-aspartic acid, L-glutamine, L-glutamic acid } \\
\text { and DL-serine }\end{array}$ & 57 & + \\
\hline Mixture minus glutamic acid & 54 & + \\
\hline Mixture minus serine & 60 & + \\
\hline Mixture minus glutamic acid and serine & 54 & + \\
\hline Mixture minus alanine & 54 & + \\
\hline Mixture minus asparagine & 60 & + \\
\hline Glutamic acid & 69 & + \\
\hline Serine & 84 & + \\
\hline \multicolumn{3}{|l|}{ Experiment 3} \\
\hline MM liquid & 129 & - \\
\hline \multicolumn{3}{|l|}{ MM liquid plus the following at $\mathrm{M}-128 \mathrm{~L}$-isomer } \\
\hline DL-valine & 126 & - \\
\hline DL-methionine & 123 & - \\
\hline DL-isoleucine & 117 & - \\
\hline L-lysine $\mathrm{HCl}$ & 114 & - \\
\hline Glycine & 108 & - \\
\hline \multicolumn{3}{|l|}{$\begin{array}{l}\text { Mixture of DL- } \alpha \text {-alanine, L-asparagine, } \\
\text { L-proline, L-aspartic acid, L-glutamine, L-glutamic } \\
\text { acid and DL-serine }\end{array}$} \\
\hline Experiment 4 & & \\
\hline MM liquid & 111 & - \\
\hline \multicolumn{3}{|l|}{ MM liquid casamino acids at $(\%, w / v)$} \\
\hline 0.003 & 111 & - \\
\hline 0.01 & 108 & $+\mathrm{i}$ \\
\hline 0.03 & 96 & + \\
\hline 0.09 & 81 & + \\
\hline $0 \cdot 27$ & 60 & + \\
\hline \multicolumn{3}{|l|}{ Experiment 5} \\
\hline $\begin{array}{l}\text { Nutrient broth prepared without deliberately } \\
\text { adding } \mathrm{NaCl}\end{array}$ & 68 & - \\
\hline $\begin{array}{l}\text { Nutrient broth which contained } 0.5 \%(w / v) \\
\text { added } \mathrm{NaCl}\end{array}$ & 44 & + \\
\hline $\begin{array}{l}\text { Nutrient broth which contained } 1 \%(w / v) \text { added } \\
\mathrm{NaCl}\end{array}$ & 42 & + \\
\hline $\begin{array}{l}\text { Nutrient broth which contained } 3 \%(w / v) \text { added } \\
\mathrm{NaCl}\end{array}$ & 60 & - \\
\hline
\end{tabular}

appear from every part of inoculum edge. 
rates on solid media, growth rates in liquid equivalents of various agar media were measured. The assumption was made that the growth rates in aerated liquid media were comparable with those on the surface of corresponding agar media. The results from three experiments in which growth rates in MM liquid in the presence of various substances were compared with ability of these substances to support swarming on MM agar are given in Table 2 (Expts. 1-3). The growth rate in MM liquid which contained one or more substances known to support swarming was higher than the growth rate in MM liquid alone or in MM liquid which contained substances which did not support swarming. Another experiment (Table 2, Expt. 4) showed the effect of decreasing the concentration of Casamino acids, a preparation which supported swarming. The growth rate was decreased when the concentration of Casamino acids added to MM liquid was decreased from an amount which supported swarming on MM agar to an amount which did not.

Another system in which the relationship between growth rate and swarming could be studied was suggested by the work of Naylor $(1960,1964)$ and Sandys $(1960)$ which showed that increasing or decreasing the concentration of $\mathrm{NaCl}$ in nutrient agar gave media which did not support swarming. We found that the growth rate in our nutrient broth (which contained $0.5 \%, \mathrm{w} / \mathrm{v}$, added $\mathrm{NaCl}$ ) and in nutrient broth which contained $1 \%(\mathrm{w} / \mathrm{v})$ added $\mathrm{NaCl}$ was higher than in nutrient broth without any added $\mathrm{NaCl}$ and in nutrient broth which contained $3 \%(\mathrm{w} / \mathrm{v})$ added $\mathrm{NaCl}$ (Table 2, Expt. 5). These differences in growth rate could be correlated with the fact that swarms developed on nutrient agar which contained $0.5 \%$ or $1 \%(\mathrm{w} / \mathrm{v})$ added $\mathrm{NaCl}$ but did not develop on nutrient agar which contained less or more $\mathrm{NaCl}$.

Table 2 shows that there was not a specific value for growth rate which was exceeded in the liquid equivalents of all solid media which supported swarming. For example, nutrient broth without $\mathrm{NaCl}$ allowed a mean generation time of $68 \mathrm{~min}$. and this medium when solidified with agar did not support swarming (Expt. 5): in contrast, MM liquid $+0.03 \%(w / v)$ Casamino acids allowed a mean generation time of $96 \mathrm{~min}$. and this medium when solidified with agar did support swarming (Expt. 4).

One other relationship was found between growth characteristics in liquid media and the development of swarms on comparable agar media. On various agar media swarms of different widths were produced although the corresponding liquid media supported similar growth rates. These differences in swarm widths were related to differences in the lengths of the lag phase in the various liquid media.

\section{DISCUSSION}

Despite suggestions that the swarming of Proteus is a response to a depletion of nutrients or to accumulation of toxic metabolic products there is little information on which to develop a satisfactory explanation for the phenomenon. The study of the phenomenon of swarming is difficult because swarming occurs intermittently and only on solid (agar, gelatin) media. Our studies and those of other workers (see Jones \& Park, 1967) have shown that the occurrence of swarming of Proteus is always associated with the change from short forms to long forms and that long forms are not formed in liquid media (but see Kvittingen, 1949a).

Amino acid requirements for morphological changes of some micro-organisms have been reported. SentheShanmaganathan \& Nickerson (1962) found that methio- 
nine was required for the formation of the triangular form of Trigonopsis variabilis. Ensign \& Wolfe (1964) found that lysine, asparagine, arginine or phenylalanine were required for the conversion of coccal forms to rod forms of Arthrobacter crystallopoietes. We found that swarming of Proteus, and therefore conversion from short to long forms, occurred when various amino acids were added to a minimal growth medium agar. The requirement did not appear to be for a particular amino acid and it seemed that the amino acids acted by stimulating growth rate. Naylor (1964) proposed a relationship between the total amount of cell material produced and the occurrence of swarming. He found that a medium which did not support swarming, i.e. nutrient agar prepared without deliberate addition of $\mathrm{NaCl}$, did do so when other electrolytes or certain carbohydrates were added. He showed by growth studies on equivalent liquid media that addition of equi-osmolar concentrations of $\mathrm{NaCl}$ or dulcitol, additions which supported swarming on agar media, promoted greater amounts of growth of the strain of Proteus vulgaris used than did addition of an equi-osmolar concentration of glucose, which did not support swarming. An examination of Naylor's results reveals that besides increased total amounts of cell material produced, faster growth rates occurred when $\mathrm{NaCl}$ or dulcitol was added than when glucose was added; so it appears from these and our results that the important effect of added compounds is on the growth rate.

The correlation we found between growth rate and the occurrence of swarming of Proteus may provide an explanation for the change in the relationship of the syntheses of various cell components which leads to the formation of long forms. Sud \& Schaechter (1964) showed that in media which supported high growth rate the amount of cell wall and cell membrane of Bacillus megaterium produced per unit of bacterial dry weight was less than when this organism was grown on media which supported lower growth rates. If a similar pattern occurs with Proteus it is conceivable that at high growth rates synthesis of these components decreases to such a degree that on agar media cell division does not keep pace with other processes and long forms are produced which can move over the surface. However, it is not yet clear how increases in growth rate bring about these changes. Perhaps substances required for cell division and for other growth processes, e.g. magnesium and potassium ions (Webb, 1949, 1953; Shankar \& Bard, 1952) or amino acids, become limiting by insufficient rate of entry or of synthesis during the stage of rapid growth and are preferentially used for processes other than cell division. Or perhaps volatile toxic products like those postulated by Lominski \& Lendrum (1947) and Hughes (1957) to explain swarming of Proteus may be produced more rapidly at high growth rates and so reach effective local concentrations only under these conditions. Volatile products of this kind were not detected by Jones (1966) and so this possibility was not investigated.

No threshold value can be given for growth rate beyond which swarms will occur, because growth rates in liquid media equivalent to nutrient agar which had been modified to inhibit swarming were higher than in minimal growth liquid media containing compounds which stimulated swarming. However, if swarming does result from a change in balance of synthesis of some cell components brought about by changes in growth rate the change in balance would be unlikely to occur at the same growth rate on media of widely different composition; the existing balance between synthesis of various components would be expected to be markedly different. 
There remains to be considered the effect on swarming of changes in temperature. Since changes in temperature cause changes in growth rate it might be expected that the occurrence of swarming would be readily affected by changes in temperature. This is not so (Kvittingen, 1949a); media which support swarming do so over a wide temperature range. Some findings of Schaechter, Maaløe \& Kjeldgaard (1958) may help to explain this apparent discrepancy. These workers showed that in a given medium the bacterial size and the composition (average mass, RNA, DNA, number of nuclei per organism) of Salmonella typhimurium were almost independent of temperature; that is, almost independent of changes in growth rate brought about by changes in temperature. Only changes in growth rate brought about by growth on different media resulted in changes in bacterial size and composition.

We wish to thank Mr N. G. J. Gruber for taking the photograph.

\section{REFERENCES}

BEYERINCK, M. W. (1889). L'auxanographie, ou la méthode de l'hydrodiffusion dans la gélatine appliquée aux recherches microbiologiques. Archs. néerl. Sci. 23, 367.

Belyavin, G. (1951). Cultural and serological phases of Proteus vulgaris. J. gen. Microbiol. $5,197$.

CoETZEe, J. N. \& SACKs, T. G. (1960). Morphological variants of Proteus hauseri. J. gen. Microbiol. 23, 209.

Dienes, L. (1946). Reproductive processes in Proteus cultures. Proc. Soc. exp. Biol. Med. 63, 265.

ENSIGN, J. C. \& WolfE, R. S. (1964). Nutritional control of morphogenesis in Arthrobacter crystallopoietes. J. Bact. 87, 924.

FILDEs, P. (1938). The growth of Proteus on ammonium lactate plus nicotinic acid. Br. J. exp. Path. $19,239$.

HAUSER, G. (1885). Über Fäulnissbacterien und deren Beziehungen zur Septicamie. Leipzig: F. G. W. Vogel.

Hoeniger, J. F. M. (1964). Cellular changes accompanying the swarming of Proteus mirabilis. I. Observations of living cultures. Can. J. Microbiol. 10, 1.

Hughes, W. H. (1957). A reconsideration of the swarming of Proteus vulgaris. J. gen. Microbiol. $17,49$.

Jones, H. E. (1966). The Swarming Phenomenon of the Bacterial Genus Proteus. Ph.D. thesis, University of Reading.

Jones, H. E. \& PARK, R. W. A. (1967). The short forms and long forms of Proteus. J. gen. Microbiol. 47, 359.

KLIENEBERGER-NOBEL, E. (1947). Morphological appearances of various stages in B. proteus and E. coli. J. Hyg., Camb. 45, 410 .

Kvittingen, J. (1949a). Studies of the life-cycle of Proteus Hauser, Part I. Acta. path. microbiol. scand. 26, 24.

Kvitingan, J. (1949b). Studies of the life-cycle of Proteus Hauser, Part II. Acta. path, microbiol. scand. 26, 855.

Lominski, I. \& Lendrum, A. C. (1947). The mechanism of swarming of Proteus. J. Path. Bact.59, 688.

MoltKe, O. (1927). Contributions to the Characterisation and Systematic Classification of Bact. proteus vulgaris (Hauser). Copenhagen: Levin and Munksgaard.

NAYLOR, P. G. D. (1960). A simple medium which controls the swarming of Proteus. J. med. Lab. Tech. 17, 182.

NAYLOR, P. G. D. (1964). The effect of electrolytes or carbohydrates in a sodium chloride deficient medium on the formation of discrete colonies of Proteus and the influence of these substances on growth in liquid culture. J. appl. Bact. 27, 422.

Pontecorvo, G. (1949). Auxanographic techniques in biochemical genetics. J. gen. Microbiol. $3,122$.

Russ-Münzer, A. (1935). Das Schwärmphänomen bei Bacillus proteus. Zentbl. Bakt. (1 Abt. Orig.), 133, 214.

SANDYs, G. H. (1960). A new method of preventing swarming of Proteus spp. with a description of a new medium suitable for use in routine laboratory practice. J. med. Lab. Tech. 17, 224.

Schaechter, M., MaAløe, O. \& KJeldgaARd, N. O. (1958). Dependency on medium and temperature of cell size and chemical composition during balanced growth of Salmonella typhimurium. J. gen. Microbiol. 19, 592. 
SentheShanmuganathan, S. \& Nickerson, W. J. (1962). Nutritional control of cellular form in Trigonopsis variabilis. J. gen. Microbiol. 27, 437.

Shankar, K. \& BARD, R. C. (1952). The effect of metallic ions on the growth and morphology of Clostridium perfringens. J. Bact. 63, 279.

Sud, I. J. \& SCHAECHTER, M. (1964). Dependence of the content of cell envelopes on the growth rate of Bacillus megaterium. J. Bact. 88, 1612.

WEBB, M. (1949). The influence of magnesium on cell division. 2. The effect of magnesium on the growth and cell division of various bacterial species in complex media. J. gen. Microbiol. 3, 410.

WEBB, M. (1953). Effects of magnesium on cellular division in bacteria. Science, N.Y. 118, 607.

\section{EXPLANATION OF PLATE}

Photograph of a swarm of Proteus mirabilis NCDO 1881 on a nutrient agar $9 \mathrm{~cm}$. plate. The plate was inoculated at the centre with 1 drop of a suspension of organism and was incubated for $20 \mathrm{hr}$ at $37^{\circ} \times 1 \cdot 3$. 


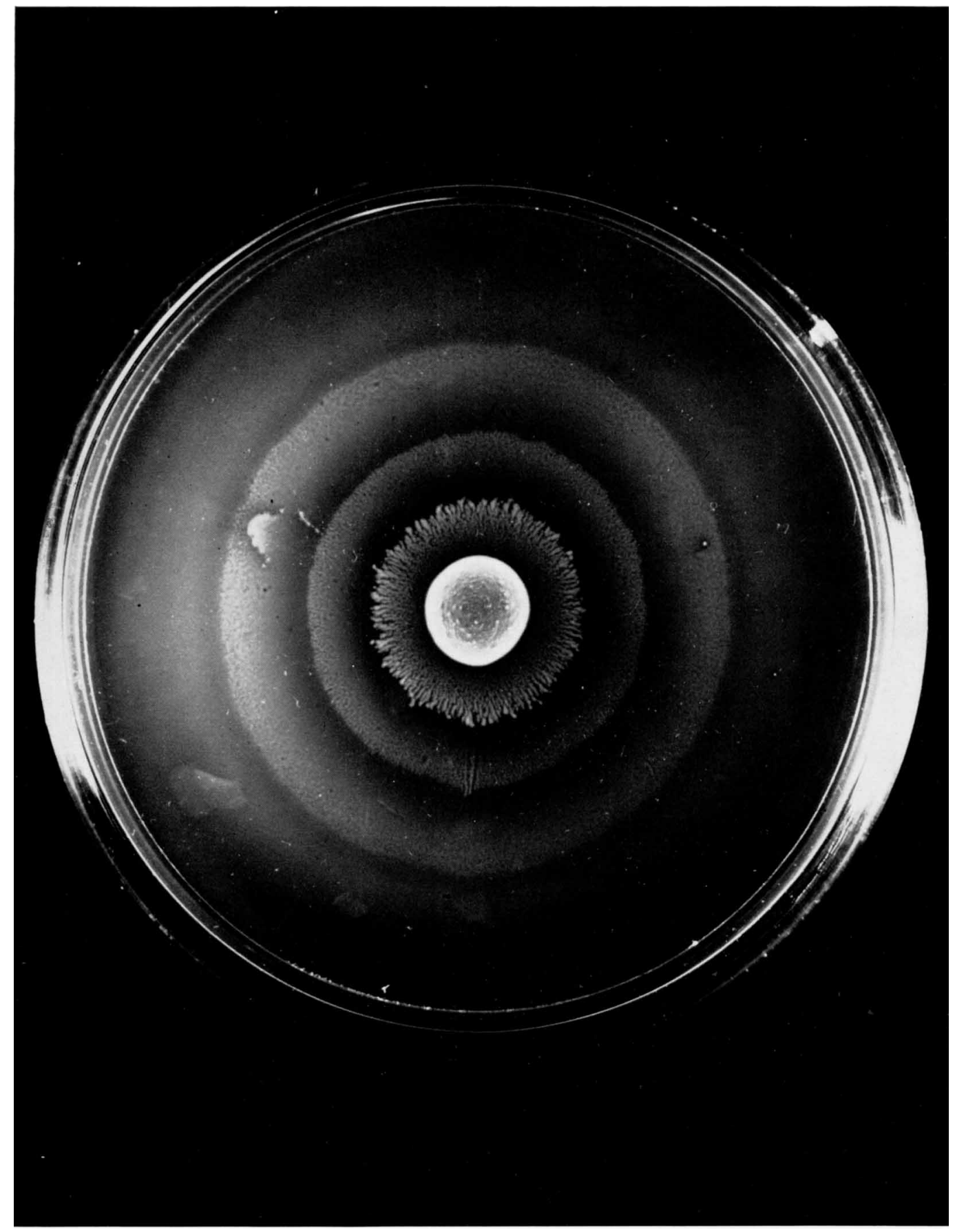

